\title{
Association between preoperative frailty and outcomes among adults undergoing cardiac surgery: a prospective cohort study
}

\author{
Carmel Montgomery RN PhD, Henry Stelfox MD PhD, Colleen Norris RN PhD, Darryl Rolfson MD, \\ Steven Meyer MD PhD, Mohamad Zibdawi MD, Sean Bagshaw MD MSc
}

Abstract

Background: The identification of frailty before complex and invasive procedures may have relevance for prognostic and recovery purposes, to optimally inform patients, caregivers and clinicians about perioperative risk and postoperative care needs. The aim of this study was to estimate the prevalence of frailty and describe the associated clinical course and outcomes of patients referred for nonemergent cardiac surgery.

Methods: A prospective cohort of patients aged 50 years and older referred for nonemergent cardiac surgery in Alberta, Canada, from November 2011 to March 2014 were screened preoperatively for frailty, defined as a Clinical Frailty Scale (CFS) score of 5 or greater. Postoperatively, patients were followed by telephone to assess CFS score, health services use and vital status. The primary outcome was all-cause hospital mortality. Secondary outcomes included health services use, hospital discharge disposition, 1-year health-related quality of life and all-cause 5-year mortality.

Results: The cohort $(n=529)$ had a mean age of 67 (standard deviation [SD] 9) years; $25.9 \%$ were female, and the prevalence of frailty was $9.6 \%(n=51 ; 95 \%$ confidence interval [Cl] 7.3\%-12.5\%). Frail patients were older (median age 75, interquartile range [IQR] 65-80 v. 67, IQR 60-73, yr; $p<0.001)$, were more likely to be female (51.0\% v. $23.2 \% ; p<0.001)$, had a higher mean EuroSCORE II $(8$, SD 3 v. 5, SD $3 ; p<0.001)$ and received combined coronary artery bypass grafting and valve procedures more frequently $(29.4 \%$ v. $15.9 \% ; p=0.02$ ) than nonfrail patients. Postoperatively, frail patients had a longer median duration of stay in the cardiovascular intensive care unit (median difference 2.2, 95\% Cl 1.60-2.79) and hospital (median difference 9.3, 95\% Cl 8.2-10.3). Hospital mortality was $9.8 \%$ among frail patients and $1.0 \%$ among nonfrail patients (adjusted hazard ratio 3.84, 95\% $\mathrm{Cl} 0.90-16.34$ ).

Interpretation: Preoperative frailty was present in $10 \%$ of patients and was associated with a higher risk of morbidity and greater health services use. Preoperative frailty has important implications for the postoperative clinical course and resource utilization of patients undergoing cardiac surgery.

F railty, defined as a state of exaggerated vulnerability to adverse health outcomes owing to the accumulation of age-related deficits, is increasingly recognized as an important factor associated with suboptimal outcomes for patients undergoing cardiac surgery. ${ }^{1-4}$ Despite this association, there is no consistent screening strategy for frailty and limited incorporation of frailty-related functional measures into cardiac surgery risk scores or proven care pathways to mitigate the perioperative risk for vulnerable patients living with frailty.

As the Canadian population ages, the incidence of frailty and concomitant cardiovascular disease prompting consideration for complex interventions are expected to grow..$^{5-7}$ Advances in intensive care and anesthetic and surgical techniques have improved outcomes, translating into older, more complex patients now routinely undergoing cardiac surgery. ${ }^{5}$

Identifying patients with frailty before cardiac surgery may have relevance for prognostic and recovery purposes and support future improvement in care processes to better inform patients, caregivers, surgeons and decision-makers about preoperative opportunities (e.g., prehabilitation), perioperative risks, and short and longer-term postoperative care needs. The aim of this study was to estimate the prevalence of frailty and describe the associated clinical course and outcomes of patients referred for nonemergent cardiac surgery.

Competing interests: Sean Bagshaw reports grants and personal fees from Baxter, and personal fees from CNA Diagnostics and BioPorto, outside the submitted work. No other competing interests were declared.

This article has been peer reviewed.

Correspondence to: Carmel Montgomery, carmelm@ualberta.ca CMAJ Open 2021. DOI:10.9778/cmajo.20200034 


\section{Methods}

\section{Design and population}

This was a prospective observational cohort study. Patients aged 50 years and older referred to the adult $(\geq 18 \mathrm{yr})$ cardiac surgery programs at the Foothills Medical Centre in Calgary and the Mazankowski Alberta Heart Institute in Edmonton, Alberta, Canada, for nonemergent surgery between November 2011 and March 2014 were eligible for enrolment. The 2 cardiac surgery centres are high-volume academic programs that provide all cardiac surgical interventions for Alberta and take complex cases referred from neighbouring provinces and territories. Patients were excluded from the study if they were referred for emergent surgery, were scheduled to receive transcatheter aortic valve implantation or were receiving cardiac transplantation.

\section{Setting}

The 2 adult cardiac surgery programs perform an average of 2800 adult surgical procedures annually, 96\% of which are nonemergent. ${ }^{8,9}$ The most common surgeries performed are isolated coronary artery bypass grafting (CABG) in 49\%, isolated valve procedures in $10 \%$, and combined CABG and valve procedures in $8 \%$ of patients. ${ }^{10,11}$ After surgery, patients are admitted to dedicated, closed-model, cardiovascular surgical intensive care units (CVICUs) staffed by board-certified intensivists available 24 hours per day. Patients are supported in a 24-bed CVICU with 10 cardiac surgeons in Edmonton and an 18-bed CVICU with 9 cardiac surgeons in Calgary. ${ }^{8,9}$ The estimated median stay in the CVICU and hospital are 2 and 7 days, respectively. Risk-adjusted 30-day in-hospital mortality after isolated CABG is $1.4 \% . .^{10,11}$

\section{Measure of frailty}

Frailty was assessed using the validated 9-point ordinal Clinical Frailty Scale (CFS), a subjective global assessment of fitness (or degree of frailty). ${ }^{12-15}$ The CFS has been extensively validated in community and acute care settings, and has commonly been used as a dichotomous descriptor of frailty status, with frailty defined as a CFS score of 5 or greater. ${ }^{12,16}$ The CFS can be further stratified into domains of fit (CFS score of 1-3), vulnerable (CFS score of 4) and frail (CFS score of 5-9) to assess for greater granularity in relative fitness or frailty. ${ }^{16}$

Frailty assessment was completed independently by research coordinators trained on the use of the CFS. ${ }^{16}$ Patients were assigned a CFS score after review of their health records and by scripted English interview in preadmission clinic or inpatient hospital settings before scheduled surgery. The abilities and condition of the patient 2 weeks before the index admission were considered in the assessment of the preoperative CFS score.

\section{Data sources}

Electronic and paper hospital health records were reviewed by research coordinators, and data were captured on standardized case report forms for later entry into an electronic study database. Before the project start, protocol specifics were piloted, including screening, recruitment and the case report forms. Results were compared after recruitment of the first 10 patients to ensure data were feasible to obtain, and complete and consistent among research coordinators, and the process was acceptable to patients. Comorbidities, and perioperative and postoperative complications were considered not present if no documentation was found to confirm their presence.

During the preoperative patient interview, research coordinators collected data on sociodemographic characteristics (i.e., age, sex, ethnicity, marital status, education, employment status and living arrangement), functional status (i.e., support at home, history of falls, memory loss, weight loss, CFS score, and Timed Up and Go test ${ }^{17}$ ), and health-related quality of life (HRQL) using the EuroQol 5-dimension 3-level (EQ-5D) health questionnaire with visual acuity scale (EQ-VAS scores ranging from 0 to 100 , with higher scores indicating higher HRQL). ${ }^{18-20}$ Further health details potentially related to frailty were captured, including body mass index, home medications and comorbid conditions (i.e., presence of congestive heart failure, peripheral vascular disease, permanent pacemaker, implanted defibrillator, aortic valve stenosis, previous cardiac surgery, pulmonary arterial hypertension, peptic ulcer disease, malignancy, rheumatoid arthritis, neurologic dysfunction, chronic kidney disease, most recent serum creatinine level and hospitalizations in the previous 12 months). Global cardiac surgery mortality risk scores, EuroSCORE $\mathrm{II}^{21}$ and Parsonnet Score, ${ }^{22}$ were also obtained from preoperative clinician assessment and patient-completed documentation in the health record. Charlson Comorbidity Index score was calculated from administrative data collected from the Alberta Health Services Discharge Abstract Database. ${ }^{23}$

Research coordinators reviewed health records to collect information related to the cardiac surgery: perioperative details (i.e., surgery type performed, duration of aortic crossclamp and cardiopulmonary bypass); postoperative course in CVICU, including duration of stay and intensity of organ support (i.e., duration of vasoactive medication and mechanical ventilation); complications (i.e., atrial fibrillation, thoracic bleeding, atrioventricular block, delirium, acute kidney injury and acute myocardial infarction); subsequent interventions (i.e., blood product transfusion, left ventricular assist device, cardiac catheterization, pulmonary arterial catheter, cardiac tamponade, epicardial pacing, pacer wire insertion, intraaortic balloon pump, defibrillation, cardioversion, cardiopulmonary resuscitation, re-exploration in operating room, extracorporeal membrane oxygenation, re-intubation, tracheostomy, total parenteral nutrition, tube feed, endoscopy, gastrointestinal surgery, renal replacement therapy and mortality); and post-CVICU hospital stay (i.e., CVICU readmission, discharge disposition and mortality).

At 6 months and 12 months after surgery, survivors were contacted via telephone by research coordinators to ascertain CFS score, HRQL and living arrangements (i.e., independent at home, at home with help, lodge or facility) using scripted text in English. Vital status was obtained from 2 data sources current to Apr. 30, 2019: the Alberta Health Services inpatient Discharge Abstract Database, which captures provincial inpatient demographic, administrative and clinical data; and the Alberta 
Provincial Project for Outcomes Assessment in Coronary Heart Disease, a registry of prospectively collected cardiac procedure details, including vital status updates from Government of Alberta Vital Statistics every 4 months. ${ }^{24,25}$ Facility health record number or the Alberta 9-digit unique personal health number were used to link with the additional data sources.

\section{Main exposure and outcome measures}

The primary exposure was preoperative frailty. The primary outcome was all-cause hospital mortality. Secondary outcomes included intensity of organ support (i.e., receipt and duration of mechanical ventilation, vasoactive therapy and renal replacement therapy); hospital discharge disposition (i.e., home, subacute rehabilitation and skilled nursing facility); health services use (i.e., duration of stay in CVICU and hospital); HRQL presurgery, at 6 months and at 12 months; and mortality in CVICU and at 6 months, 12 months and 5 years after surgery.

\section{Statistical analysis}

Descriptive statistics were tabulated by a CFS score of 5 or greater (frail) compared with a CFS score of 4 or less (nonfrail). Univariate comparisons were performed to evaluate the association of frailty and the primary and secondary outcomes. Symmetrically distributed continuous data were reported as means with standard deviations (SDs) and compared using the Student $t$ test. Skewed continuous data were reported as medians with interquartile ranges (IQRs), compared using the Mann-Whitney $U$ test and adjusted differences obtained from quantile regression. Categorical variables were compared using the $\chi^{2}$ test for independence.

Multivariable logistic regression was used to describe factors associated with binary secondary outcomes. The association of frailty and continuous outcomes were explored using linear regression. Cox proportional hazards regression was used to estimate hazard ratios (HRs) with 95\% confidence intervals (CIs) for CVICU, hospital, 6-month, 12-month and 5 -year mortality. Models included a priori selected variables perceived to have clinical importance: age, sex, EuroSCORE II and frailty. A $p$ value less than 0.05 was considered significant for all statistical tests. Missing CFS scores were imputed using mean of scores assigned by an expert 5-person panel including 1 geriatric medicine specialist (D.R.), 2 critical care physicians (S.B.), 1 research coordinator and 1 nurse researcher (C.M.) who independently reviewed patient case report forms to assess frailty. Analyses were performed using Stata 16 (StataCorp).

\section{Ethics approval}

This study was approved by the research ethics board at the University of Alberta, Edmonton (ID Pro00074770). Participant consent was obtained at the time of enrolment.

\section{Results}

In total, 529 patients were included, with a mean age of 67 (SD 9) years; $25.9 \%(n=137)$ were female, $79.0 \%(n=418)$ lived with a spouse, $53.7 \%(n=284)$ were unemployed or retired, and 54.4\% $(n=288)$ reported receiving help at home. Isolated valve procedures $(41.4 \%, n=219)$, followed by isolated CABG surgery $(38.2 \%, n=202)$, and combined CABG and valve surgery $(17.2 \%, n=91)$ were the most common cardiac procedures performed. The median EuroSCORE II was 5 (IQR 3-7), and $6.0 \%(n=32)$ of patients had received prior cardiac surgery (Table 1$)$.

The prevalence of frailty was $9.6 \%(n=51,95 \%$ CI $7.3 \%-$ $12.5 \%$ ), ranging from $2.3 \%$ in patients younger than 55 years to $33.3 \%$ in those 85 years and older. Postoperatively, the median duration of stay was 1 (IQR 1-3) day and 7 (IQR 6-11) days in CVICU and in hospital, respectively. Mortality in CVICU was $0.8 \%(n=4$; $95 \%$ CI $0.2 \%-1.9 \%)$, in hospital was $1.9 \%(n=10 ; 95 \%$ CI $0.9 \%-3.4 \%)$ and at 5 years postsurgery was $12.5 \%(n=66 ; 95 \%$ CI 9.8\%-15.6\%) (Table 2, Figures 1 and 2). Vital status was unavailable for 5 patients owing to out-of-province residence $(5 / 529,0.9 \%)$. Twentyone patients $(4.0 \%, 95 \%$ CI $2.5 \%-6.0 \%)$ were re-admitted to the CVICU during their index hospitalization.

\section{Patient characteristics stratified by frailty status}

Frail patients were older than nonfrail patients (median 75, IQR 65-80 v. 67, IQR 60-73, yr; $p<0.001$ ), were taking more prescribed medications (6, IQR 4-10 v. 5, IQR 3-7; $p<$ 0.001), had higher EuroSCORE II scores (mean 8, SD 3 v. 5 , SD 3; $p<0.001)$, had longer Timed Up and Go measures (18, IQR 11-27 v. 9, IQR 8-12, s; $p<0.001$ ), and were more likely to undergo combined valve and CABG surgery $(29.4 \% \mathrm{v}$. $15.9 \% ; p=0.02)$ and less likely to receive isolated CABG $(21.6 \%$ v. $40.0 \% ; p=0.01)$. Frail patients had more comorbid diseases and were more likely to have reported a recent history of falls $(34.7 \%$ v. $10.9 \%$; $p<0.001)$ compared with nonfrail patients (Table 1).

\section{Complications of cardiac surgery by frailty status}

Postoperative complications were more common in frail patients than in nonfrail patients. Frail patients were more likely to experience postoperative bleeding (15.7\% v. $4.8 \%$; $p=0.002)$ and acute kidney injury $(13.7 \%$ v. $4.6 \% ; p=$ $0.007)$. Frail patients received more interventions and required greater escalation of intensity of treatment, including return to the operating room $(9.8 \%$ v. $3.1 \% ; p=0.02)$, receipt of blood products $(52.9 \%$ v. $19.7 \%$; $p<0.001)$, reintubation $(11.8 \%$ v. $4.6 \% ; p=0.03)$, enteral nutrition by feeding tube $(19.6 \%$ v. $5.4 \% ; p<0.001)$ and renal replacement therapy $(11.8 \%$ v. $0.6 \% ; p<0.001)$ than those who were nonfrail (Table 3 ).

\section{Patient outcomes}

Hospital mortality was $9.8 \%$ among frail patients and was $1.0 \%$ among nonfrail patients (adjusted hazard ratio [HR] 3.84, 95\% CI 0.90-16.34). CVICU mortality for frail patients was $3.9 \%$, compared with $0.4 \%$ in nonfrail patients (adjusted HR 1.43, 95\% CI 0.12-16.72). The adjusted HRs at 6 months (9.8\% v. $1.5 \%$; adjusted HR 6.02, 95\% CI 1.79 20.23 ), at 12 months (11.8\% v. $2.5 \%$; adjusted HR 4.34, $95 \%$ 


\begin{tabular}{|c|c|c|c|c|}
\hline \multirow[b]{2}{*}{ Characteristic } & \multicolumn{3}{|c|}{ No. $(\%)$ of patients $†$} & \multirow[b]{2}{*}{$p$ value } \\
\hline & $\begin{array}{l}\text { Overall } \\
n=529\end{array}$ & $\begin{array}{c}\text { CFS } \geq 5 \\
n=51\end{array}$ & $\begin{array}{l}\text { CFS } \leq 4 \\
n=478\end{array}$ & \\
\hline CFS score presurgery, median (IQR) & $3(3-4)$ & $5(5-6)$ & $3(5-6)$ & $<0.001$ \\
\hline Sex, female & $137(25.9)$ & $26(51.0)$ & $111(23.2)$ & $<0.001$ \\
\hline \multicolumn{5}{|l|}{ Age, yr } \\
\hline Median (IQR) & $67(60-74)$ & $75(65-80)$ & $67(60-73)$ & $<0.001$ \\
\hline$<60$ & $124(23.4)$ & $7(13.7)$ & $117(24.5)$ & 0.08 \\
\hline $60-69$ & $198(37.4)$ & $10(19.6)$ & $188(39.3)$ & 0.01 \\
\hline $70-79$ & $154(29.1)$ & $19(37.3)$ & $135(28.2)$ & 0.2 \\
\hline $80-89$ & $53(10.0)$ & $15(29.4)$ & $38(7.9)$ & $<0.001$ \\
\hline Employed or volunteer $\ddagger$ & $242(45.7)$ & $9(17.6)$ & $233(48.7)$ & $<0.001$ \\
\hline Living at home independently (no help) & $240(45.4)$ & $17(33.3)$ & $223(46.7)$ & 0.07 \\
\hline Postsecondary education & $290(55.8)$ & $35(71.4)$ & $255(54.1)$ & 0.02 \\
\hline Married or common-law & $418(79.0)$ & $38(74.5)$ & $380(79.5)$ & 0.4 \\
\hline EuroSCORE II, mean \pm SD & $5 \pm 3$ & $8 \pm 3$ & $5 \pm 3$ & $<0.001$ \\
\hline Parsonnet Score, mean \pm SD & $14 \pm 8$ & $22 \pm 10$ & $13 \pm 8$ & $<0.001$ \\
\hline $\begin{array}{l}\text { Charlson Comorbidity Index score, median } \\
\text { (IQR) }\end{array}$ & $1(0-3)$ & $2(0-4)$ & $1(0-3)$ & 0.04 \\
\hline Timed Up and Go Test, s, median (IQR) & $10(8-12)$ & $18(11-27)$ & $9(8-12)$ & $<0.001$ \\
\hline Timed Up and Go Test, $\leq 19 \mathrm{~s}$ & $469(91.4)$ & $24(55.8)$ & $445(94.7)$ & $<0.001$ \\
\hline \multicolumn{5}{|l|}{ Surgery type } \\
\hline Isolated CABG & $202(38.2)$ & $11(21.6)$ & $191(40.0)$ & 0.01 \\
\hline Isolated valve (any valve) & $219(41.4)$ & $24(47.1)$ & $195(40.8)$ & 0.4 \\
\hline Combined CABG and valve & $91(17.2)$ & $15(29.4)$ & $76(15.9)$ & 0.02 \\
\hline Myomectomy, ASD or myxoma & $9(1.7)$ & $0(0)$ & $9(1.9)$ & - \\
\hline Isolated proximal aorta & $8(1.5)$ & $1(2.0)$ & $7(1.5)$ & 0.8 \\
\hline \multicolumn{5}{|l|}{ Presurgical conditions - cardiac } \\
\hline Congestive heart failure & $80(15.1)$ & $17(33.3)$ & $63(13.2)$ & $<0.001$ \\
\hline Peripheral vascular disease & $58(11.0)$ & $10(19.6)$ & $48(10.0)$ & 0.04 \\
\hline Pacemaker or AICD & $18(3.4)$ & $6(11.8)$ & $12(2.5)$ & 0.001 \\
\hline Aortic valve stenosis & 227 (42.9) & $31(60.8)$ & $196(41.0)$ & 0.01 \\
\hline Previous cardiac surgery & $32(6.0)$ & $3(5.9)$ & $29(6.1)$ & $>0.9$ \\
\hline Pulmonary arterial hypertension & $47(8.9)$ & $11(21.6)$ & $36(7.5)$ & 0.001 \\
\hline
\end{tabular}

CI 1.54-12.19) and 5 years postsurgery (25.5\% v. $11.1 \%$; adjusted HR 2.21, 95\% CI 1.16-4.21) represent greater rate of death for frail than nonfrail patients (Table 2, Figure 3). Cox proportional hazards analysis using 3-level and 4-level CFS score strata showed gradient increases in mortality at 12 months with increasing CFS scores (Table 4).

\section{Health services use}

Measures of health services use were frequently greater in frail patients than in nonfrail patients in adjusted analyses. Median duration of vasoactive medication administration was 1 (IQR $0.3-3$ ) day in frail patients and 0.5 (IQR $0.2-1$ ) day in nonfrail patients (adjusted median difference 1, 95\% CI 0.6-1.2). Median duration of stay in the CVICU (3, IQR 1-5 v. 1, IQR $1-3$, d; adjusted median difference $2.2,95 \%$ CI 1.6-2.8) and subsequent hospital stay after CVICU (9, IQR 6-17 v. 5, IQR 4-7, d; adjusted median difference 8.3, 95\% CI 7.4-9.2) were longer for frail patients than for nonfrail patients. Prolonged mechanical ventilation $(\geq 48 \mathrm{~h}$ ) was more frequent in frail patients than in nonfrail patients $(17.6 \%$ v. $3.3 \%$; adjusted OR 4.79, 95\% CI 1.82-12.65). Unplanned re-admissions to the CVICU during the index hospital stay occurred in $9.8 \%$ of frail patients and $3.3 \%$ of nonfrail patients (adjusted OR 2.74, 95\% CI 0.89-8.45) (Table 2). 


\begin{tabular}{|c|c|c|c|c|}
\hline \multirow[b]{2}{*}{ Characteristic } & \multicolumn{3}{|c|}{ No. $(\%)$ of patients $†$} & \multirow[b]{2}{*}{$p$ value } \\
\hline & $\begin{array}{l}\text { Overall } \\
n=529\end{array}$ & $\begin{array}{l}\text { CFS } \geq 5 \\
n=51\end{array}$ & $\begin{array}{l}\text { CFS } \leq 4 \\
n=478\end{array}$ & \\
\hline \multicolumn{5}{|l|}{ Presurgical conditions - noncardiac } \\
\hline Peptic ulcer disease & $30(5.7)$ & $5(9.8)$ & $25(5.2)$ & 0.2 \\
\hline Malignant disease & 68 (12.9) & $13(25.5)$ & 55 (11.5) & 0.01 \\
\hline Rheumatoid arthritis & $81(15.3)$ & $19(37.3)$ & $62(13.0)$ & $<0.001$ \\
\hline Neurologic dysfunction§ & $85(16.1)$ & $16(31.4)$ & $69(14.4)$ & 0.002 \\
\hline $\begin{array}{l}\text { Creatinine level, presurgery, } \mu \mathrm{mol} / \mathrm{L} \text {, } \\
\text { mean } \pm \mathrm{SD}\end{array}$ & $91 \pm 47$ & $97 \pm 39$ & $91 \pm 48$ & 0.2 \\
\hline Chronic kidney diseaseף & $6(1.1)$ & $2(3.9)$ & $4(0.8)$ & 0.1 \\
\hline $\mathrm{BMI}$, mean $\pm \mathrm{SD}$ & $30 \pm 6$ & $31 \pm 6$ & $30 \pm 6$ & 0.4 \\
\hline $\mathrm{BMI}<19$ or $>29$ & $232(43.9)$ & $25(49.0)$ & $207(43.3)$ & 0.4 \\
\hline History of falls & $69(13.1)$ & $17(34.7)$ & $52(10.9)$ & $<0.001$ \\
\hline Memory loss & $146(27.6)$ & $20(39.2)$ & $126(26.4)$ & 0.05 \\
\hline Previous 12-month hospitalizations & $128(24.6)$ & $22(44.9)$ & $106(22.5)$ & 0.001 \\
\hline Prescribed medications, median (IQR) & $5(3-7)$ & $6(4-10)$ & $5(3-7)$ & $<0.001$ \\
\hline Taking $\geq 5$ prescribed medications & $292(55.2)$ & $36(70.6)$ & $256(53.6)$ & 0.02 \\
\hline \multicolumn{5}{|l|}{ Perioperative course } \\
\hline Aorta cross-clamp, min, median (IQR) & $\begin{array}{c}86 \\
(62-114)\end{array}$ & $89(71-118)$ & $86(60-113)$ & 0.4 \\
\hline $\begin{array}{l}\text { Cardiopulmonary bypass, min, median } \\
\text { (IQR) }\end{array}$ & $\begin{array}{c}109 \\
(83-144)\end{array}$ & $111(90-162)$ & $109(82-143)$ & 0.4 \\
\hline \multicolumn{5}{|c|}{ 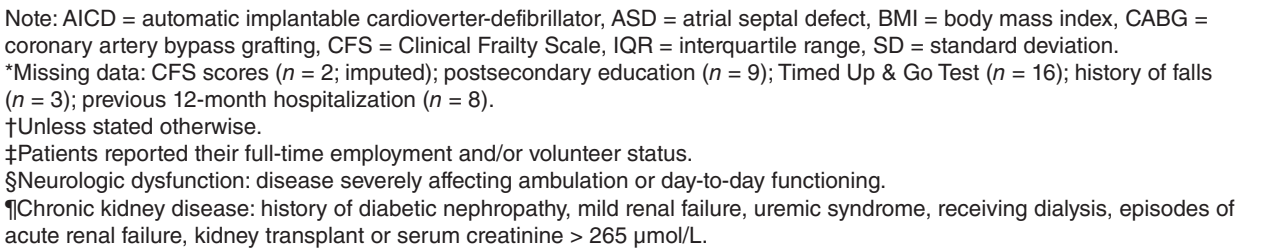 } \\
\hline
\end{tabular}

\section{Discharge disposition}

At the time of discharge from hospital, frail patients were more likely to go to a subacute care or rehabilitation centre $(19.6 \%$ v. $3.8 \%, p=0.01)$ and were less likely to go home (64.7\% v. $93.9 \%, p<0.001) ; 6 \%$ of frail patients had a new admission to a lodge or facility compared with $1 \%$ of nonfrail patients $(p=0.1)$, but this comparison was not significant (Table 2).

\section{Health-related quality of life}

Frail patients had a lower mean EQ-VAS at baseline (46.2, SD 18.9 v. 60.2, SD 20.2; adjusted mean difference 14.8, 95\% CI 8.7-20.9), at 6 months (61.6, SD 15.2 v. 73.3, SD 16.4; adjusted mean difference $11.7,95 \%$ CI 6.4-17.0) and at 12 months (60.3, SD 21.6 v. 76.6, SD 15.4; adjusted mean difference 14.9 , 95\% CI 9.5-20.2) than their nonfrail counterparts (Table 2). Frailty was associated with a 9-point decrease in EQ-VAS score at 12 months when baseline EQ-
VAS, age, sex and EuroSCORE II were held constant in a linear regression model.

\section{Interpretation}

In this prospective cohort study involving patients aged 50 years and older referred for cardiac surgery, frailty was present in $10 \%$ and was associated with longer recovery and less favourable outcomes. A higher preoperative CFS score was associated with gradient increases in long-term mortality, higher risk of postoperative complications, greater resource use and lower likelihood of return home.

Frailty screening before surgery presents an opportunity to understand and potentially modify the contributing elements of frailty on risk of adverse events, along with better approximation of expected recovery time, including duration of CVICU stay and hospitalization to assist discharge planning. ${ }^{26}$ Frailty-specific care pathways could identify vulnerable 


\begin{tabular}{|c|c|c|c|c|}
\hline \multirow[b]{2}{*}{ Variable } & \multicolumn{3}{|c|}{ No. $(\%)$ of patients* } & \multirow[b]{2}{*}{$\begin{array}{l}\text { Adjusted HR } \\
(95 \% \mathrm{Cl}) \dagger\end{array}$} \\
\hline & $\begin{array}{l}\text { Overall } \\
n=529\end{array}$ & $\begin{array}{c}\text { CFS } \geq 5 \\
n=51,9.6 \%\end{array}$ & $\begin{array}{l}\text { CFS } \leq 4 \\
n=478 \\
90.4 \%\end{array}$ & \\
\hline \multicolumn{5}{|l|}{ Mortality } \\
\hline CVICU mortality & $4(0.8)$ & $2(3.9)$ & $2(0.4)$ & $1.43(0.12$ to 16.72$)$ \\
\hline Hospital mortality & $10(1.9)$ & $5(9.8)$ & $5(1.0)$ & $\begin{array}{c}3.84(0.90 \text { to } \\
16.34)\end{array}$ \\
\hline 6-month mortality & $12(2.3)$ & $5(9.8)$ & $7(1.5)$ & $\begin{array}{l}6.02(1.79 \text { to } \\
20.23)\end{array}$ \\
\hline 12-month mortality & $18(3.4)$ & $6(11.8)$ & $12(2.5)$ & 4.34 (1.54 to 12.19$)$ \\
\hline 5-year mortality & $66(12.5)$ & $13(25.5)$ & $53(11.1)$ & 2.21 (1.16 to 4.21$)$ \\
\hline Health services use & & & & $\begin{array}{l}\text { Median difference } \\
(95 \% \mathrm{Cl}) \dagger\end{array}$ \\
\hline CVICU stay, d, median (IQR) & $1(1-3)$ & $3(1-5)$ & $1(1-3)$ & 2 (2 to 3$)$ \\
\hline $\begin{array}{l}\text { Post-CVICU hospital stay, d, } \\
\text { median (IQR) }\end{array}$ & $5(4-8)$ & $9(6-17)$ & $5(4-7)$ & 8 (7 to 9$)$ \\
\hline $\begin{array}{l}\text { Preoperative hospital stay, } d, \\
\text { mean } \pm \text { SD }\end{array}$ & $1 \pm 6$ & $2 \pm 5$ & $1 \pm 6$ & $1(-1$ to 3$)$ \\
\hline $\begin{array}{l}\text { Postoperative hospital stay, d, } \\
\text { median (IQR) }\end{array}$ & $7(6-11)$ & $12(8-25)$ & $7(6-10)$ & 9 (8 to 10$)$ \\
\hline \multirow[t]{2}{*}{$\begin{array}{l}\text { Vasoactive medication duration, } \\
\text { d, median (IQR) }\end{array}$} & $1(0.2-1)$ & $1(0.3-3)$ & $0.5(0.2-1)$ & $1(0.6$ to 1.2$)$ \\
\hline & & & & $\begin{array}{c}\text { OR } \\
(95 \% \mathrm{Cl}) \dagger\end{array}$ \\
\hline Vasoactive medication, frequency & $455(86.0)$ & $45(88.2)$ & $410(85.8)$ & $\begin{array}{c}1.35 \\
(0.53 \text { to } 3.47)\end{array}$ \\
\hline Re-admission to any ICU & $21(4.0)$ & $5(9.8)$ & $16(3.3)$ & $\begin{array}{c}2.74 \\
(0.89 \text { to } 8.45)\end{array}$ \\
\hline Mechanical ventilation $\geq 48 \mathrm{~h}$ & $25(4.7)$ & $9(17.6)$ & $16(3.3)$ & $\begin{array}{c}4.79 \\
(1.82 \text { to } 12.65)\end{array}$ \\
\hline Hospital discharge disposition & & & & $p$ value $†$ \\
\hline Home (independent or with help) & $482(91.1)$ & $33(64.7)$ & $449(93.9)$ & $<0.001$ \\
\hline Subacute care & $28(5.3)$ & $10(19.6)$ & $18(3.8)$ & 0.01 \\
\hline Lodge or facility & $9(1.7)$ & $3(5.9)$ & $6(1.3)$ & 0.1 \\
\hline Health-related quality of life & & & & $\begin{array}{l}\text { Mean difference } \\
(95 \% \mathrm{Cl}) \dagger\end{array}$ \\
\hline Baseline EQ-VAS, mean \pm SD & $58 \pm 21$ & $46 \pm 19$ & $60 \pm 20$ & 15 (9 to 21$)$ \\
\hline 6-month EQ-VAS, mean \pm SD & $72 \pm 17$ & $62 \pm 15$ & $73 \pm 16$ & $12(6$ to 17$)$ \\
\hline 12-month EQ-VAS, mean \pm SD & $75 \pm 17$ & $60 \pm 22$ & $76 \pm 15$ & 15 (10 to 20$)$ \\
\hline \multicolumn{5}{|c|}{$\begin{array}{l}\text { Note: } \mathrm{CFS}=\text { Clinical Frailty Scale, } \mathrm{CI}=\text { confidence interval, } \mathrm{CVICU}=\text { cardiovascular surgical intensive care unit, EQ-VAS = EuroQol } \\
\text { health questionnaire with visual acuity scale, } \mathrm{HR}=\text { hazard ratio, ICU = intensive care unit, IQR = interquartile range, } \mathrm{OR}=\text { odds } \\
\text { ratio, } \mathrm{SD}=\text { standard deviation. } \\
\text { *Unless stated otherwise. } \\
\text { †All reported comparisons were adjusted for age, sex and EuroSCORE II. }\end{array}$} \\
\hline
\end{tabular}

patients and ensure they have the best opportunity for recovery. ${ }^{27,28}$ Although frailty-specific pathways already exist for many noncardiac surgical interventions (e.g., colorectal procedures, ${ }^{29}$ and hip and knee arthroplasty ${ }^{30}$ ) cardiac surgical services have largely focused on postoperative targets (e.g., early extubation and mobilization ${ }^{31}$ ) to reduce duration of CVICU and subsequent acute hospital stay. A recent study described a comprehensive perioperative pathway for enhanced recovery after cardiac surgery targeting all nonemergency adult patients; however, this study did not 


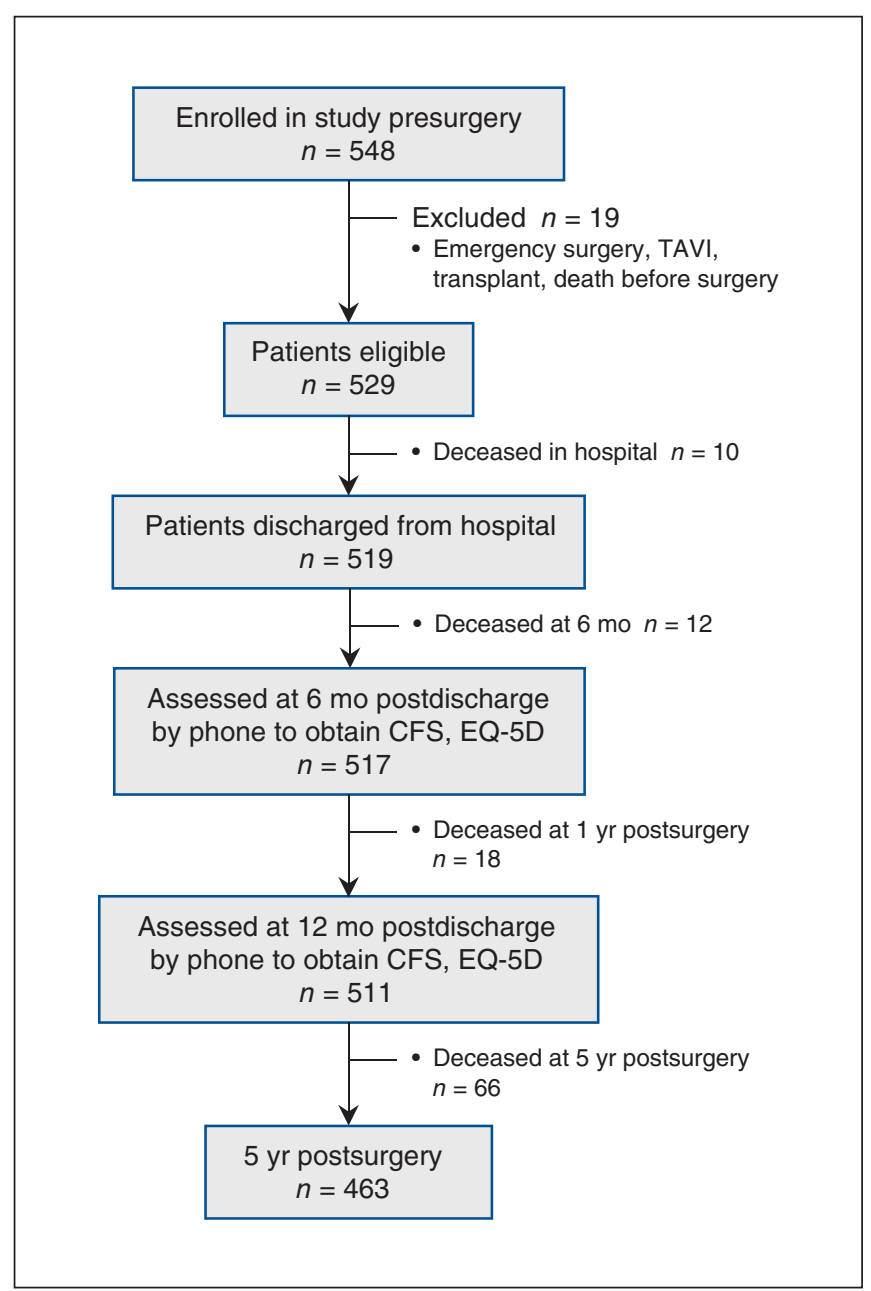

Figure 1: Patient selection for cardiovascular surgery study cohort. Note: CFS = Clinical Frailty Scale score, EQ-5D = EuroQol 5-dimension 3-level health questionnaire score and visual analogue scale, $\mathrm{TAVI}=$ transcatheter aortic valve implantation.

specifically address what may be unique domains related to frailty (e.g., cognitive [delirium], physical strength [sarcopenia], mobilization [slow gait speed], polypharmacy and susceptibility to adverse effects). ${ }^{27}$ An ideal comprehensive frailty-specific care pathway would include identification of frailty (i.e., presence, severity and driving domains) as a key factor in the preoperative phase, triggering involvement of specialist services with a frailty-focused lens to mitigate risk and enhance recovery for patients identified as frail and by targeting frailty-specific domains. ${ }^{27,32-38}$

Consent for surgery should acknowledge how frailty can modify the perioperative course and disrupt the expected recovery process by increasing the risk of adverse events, prolonging what was anticipated as "routine" cardiac surgery. Such information can better inform and empower patients and caregivers in the decision-making process and ensure that realistic expectations are clear. ${ }^{2,39,40}$ In light of the elevated risks associated with frailty, preoperative discussions should include frailty-related risk of adverse events following surgery, mortality, and potential loss of functional autonomy and independence. These details should be reconciled with individual symptoms and with what risk or trade-offs are acceptable to the patient. ${ }^{41,42}$

In addition to routine cardiac rehabilitation, post-CVICU hospital stays should aim to screen for the physical and cognitive disabilities common among frail patients after major physiologic stress. ${ }^{43,44}$ Patients who underwent cardiac surgery who accumulate further deficits or whose existing deficits worsen during their hospitalization are likely to benefit from continuity with experts in frailty to mitigate the long-term effects of such deficits (e.g., geriatric medicine), preserve autonomy and successfully transition back to the community. One reassuring finding in our study aligns with results of recent studies in which patients with frailty before cardiac surgery have seen improvements in their HRQL. ${ }^{45,46}$

The findings of this study support prior work describing the substantial effect of frailty on cardiac surgery outcomes, and the potential for value in adding a validated frailty measure to clinical risk prediction scoring systems. ${ }^{26,47,48}$ Although mobility (EuroSCORE II) and gait speed (Society of Thoracic Surgeons) have been acknowledged in recent revisions to cardiac surgery risk scoring instruments, there is an urgent need for a validated frailty measure to be added to existing cardiac surgery risk scoring instruments or development of a novel risk score focused on baseline functional status and integrated validated measures that predict postoperative outcomes beyond mortality. $26,34,47$

For health system planners, we submit that frailty may be a meaningful and measurable confounder to be integrated into adjusted outcome estimates and used to plan for every phase of cardiac surgery care adequately. The addition of a validated frailty measure, such as the CFS score or frailty index, ${ }^{49,50}$ to electronic health records, administrative databases and registries, as a routinely calculated or clinically assessed risk factor is encouraged, though this needs further investigation.

\section{Limitations}

Our study is noteworthy for its comprehensive collection of prospective preoperative validated frailty measures, risk factors, perioperative clinical course, postoperative complications and long-term objective outcomes for patients living with frailty on a provincial scale. However, our study does have several limitations. The CFS instrument was derived and validated in an older ambulatory population and has yet to be specifically evaluated against a gold standard (i.e., comprehensive geriatric assessment) in the cardiac surgery setting. Although previous studies have tested the reliability of trained research staff determining CFS scores, ${ }^{16,17}$ we did not measure interrater reliability and are unable to comment on variation among research coordinators and possible subsequent bias.

Our approach to coding comorbidities as absent if not documented may present risk of bias, although in a homogenous group of patients undergoing cardiac surgery presenting to the 2 provincial cardiac surgery centres in Alberta, we believe the risk of substantial omission or inappropriate documentation of comorbidities was minimal. This study may 


\section{Research}

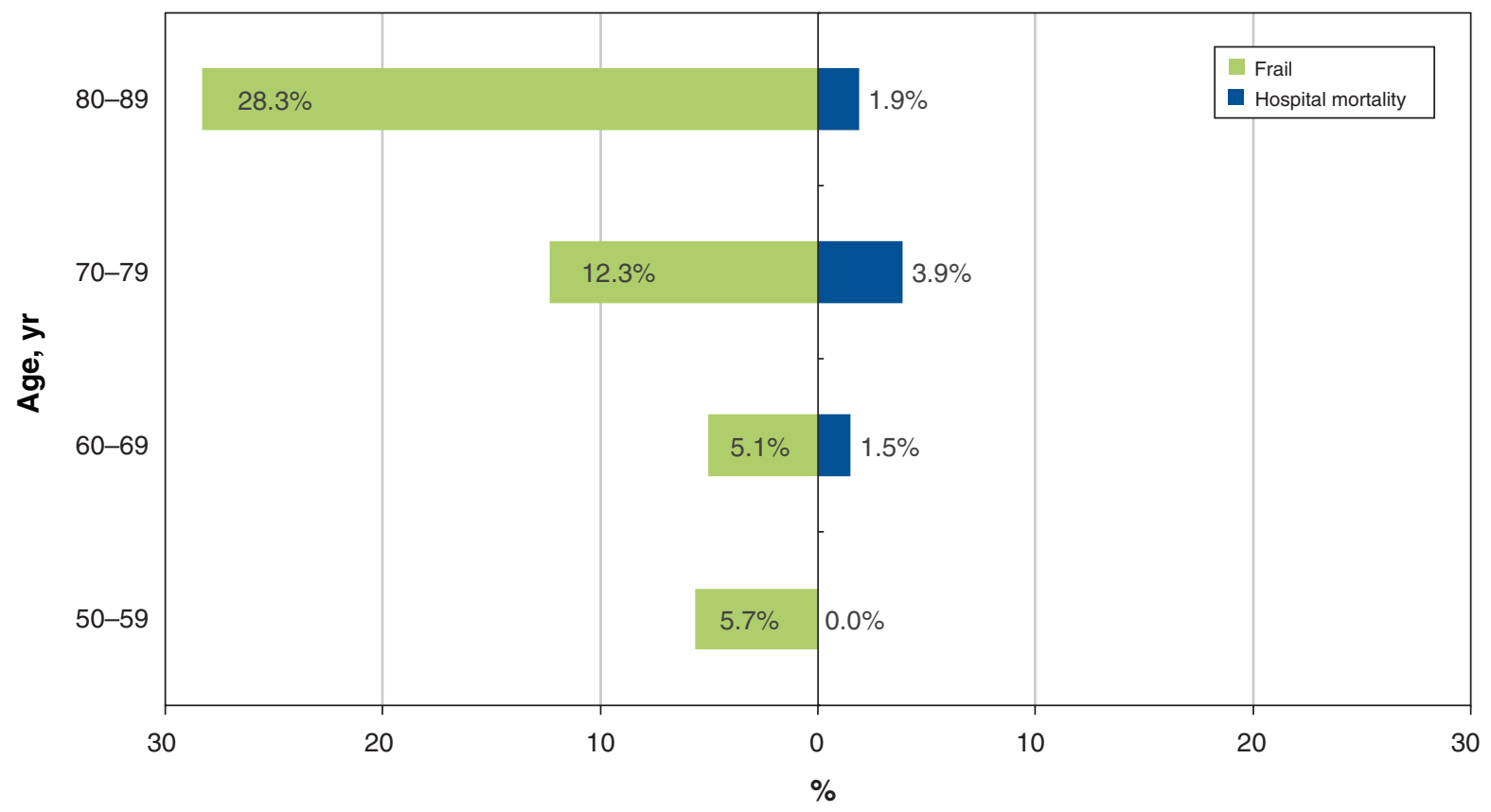

Figure 2: Prevalence of frailty and hospital mortality across age groups.

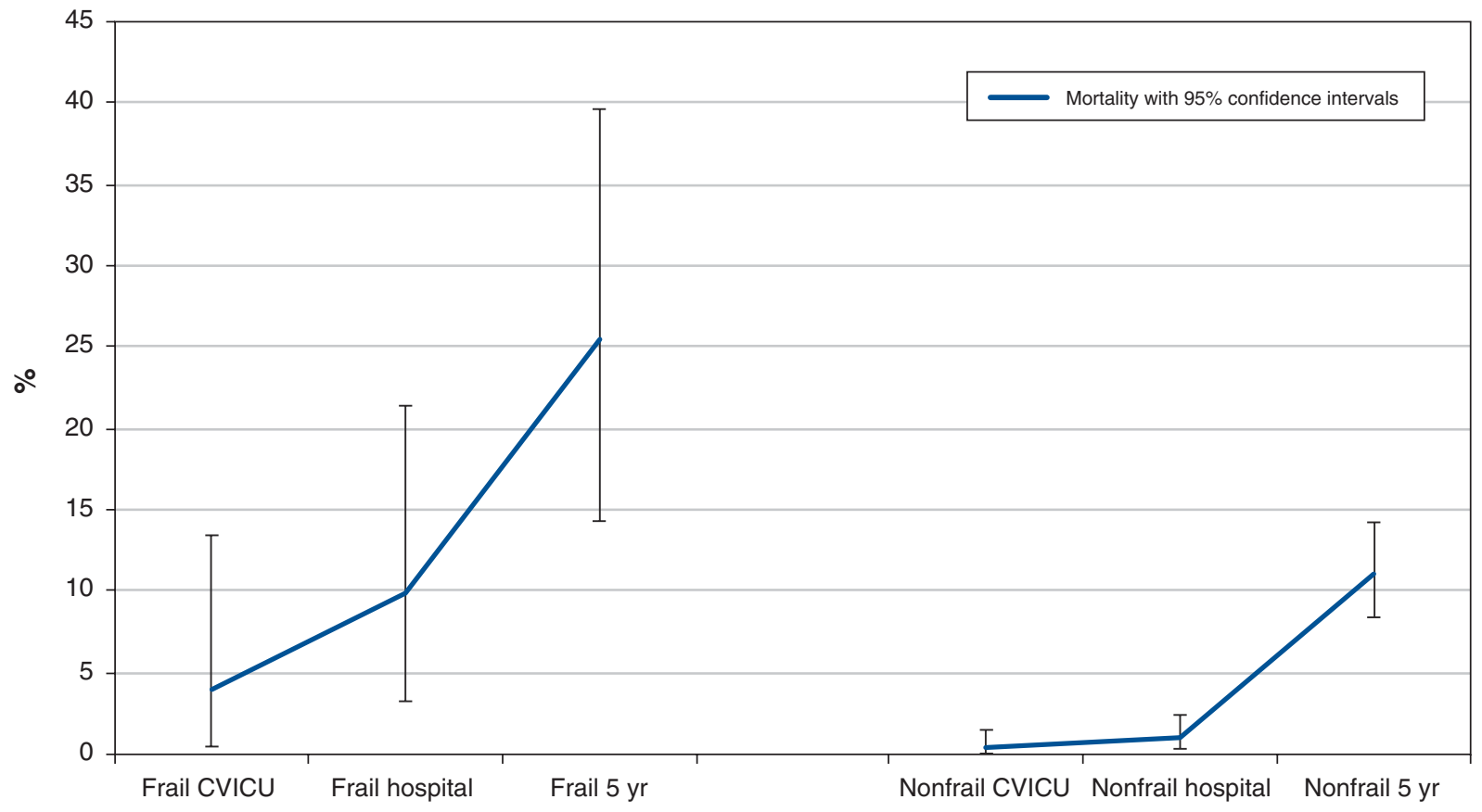

Figure 3: Mortality in cardiac surgery cohort during 5-year follow-up, stratified by Clinical Frailty Scale (CFS) score, nonfrail (CFS 1-4) versus frail (CFS 5-9). Note: CVICU = cardiovascular surgical intensive care unit. 


\begin{tabular}{|c|c|c|c|c|}
\hline \multirow[b]{2}{*}{ Variable } & \multicolumn{3}{|c|}{ No. (\%) of patients } & \multirow[b]{2}{*}{$p$ value } \\
\hline & $\begin{array}{l}\text { Overall } \\
n=529\end{array}$ & $\begin{array}{c}\text { CFS } \geq 5 \\
n=51\end{array}$ & $\begin{array}{l}\text { CFS } \leq 4 \\
n=478\end{array}$ & \\
\hline \multicolumn{5}{|l|}{ Postoperative complications } \\
\hline Atrial fibrillation & $133(25.1)$ & $15(29.4)$ & $118(24.7)$ & 0.5 \\
\hline Bleeding & $31(6.0)$ & $8(15.7)$ & $23(4.8)$ & 0.002 \\
\hline Atrioventricular block & $11(2.1)$ & 0 & $11(2.3)$ & - \\
\hline Delirium & $41(7.8)$ & $7(13.7)$ & $34(7.1)$ & 0.09 \\
\hline Acute kidney injury† & $29(5.5)$ & $7(13.7)$ & $22(4.6)$ & 0.007 \\
\hline Acute myocardial infarction & $1(0.2)$ & 0 & $1(0.2)$ & - \\
\hline \multicolumn{5}{|l|}{ Postoperative interventions } \\
\hline Transfusion & $121(22.9)$ & $27(52.9)$ & $94(19.7)$ & $<0.001$ \\
\hline Left ventricular assist device & $1(0.2)$ & $1(2.0)$ & 0 & - \\
\hline Cardiac catheterization & $3(0.6)$ & $2(3.9)$ & $1(0.2)$ & 0.03 \\
\hline Pulmonary arterial catheter & $1(0.2)$ & $1(2.0)$ & 0 & - \\
\hline Cardiac tamponade & $4(0.8)$ & $1(2.0)$ & $3(0.6)$ & 0.3 \\
\hline Epicardial pacing & $117(22)$ & $9(17.6)$ & $108(22.6)$ & 0.5 \\
\hline Pacer wire insertion & $114(22.1)$ & $12(23.5)$ & $102(21.3)$ & 0.7 \\
\hline Intra-aortic balloon pump & $3(0.6)$ & $1(2.0)$ & $2(0.4)$ & 0.2 \\
\hline Defibrillation & $16(3.0)$ & $2(3.9)$ & $14(2.9)$ & 0.7 \\
\hline Cardioversion & $27(5.1)$ & $5(9.8)$ & $22(5)$ & 0.2 \\
\hline $\begin{array}{l}\text { Cardiopulmonary } \\
\text { resuscitation }\end{array}$ & $2(0.4)$ & $1(2.0)$ & $1(0.2)$ & 0.2 \\
\hline $\begin{array}{l}\text { Re-exploration in operating } \\
\text { room }\end{array}$ & $20(3.8)$ & $5(9.8)$ & $15(3.1)$ & 0.02 \\
\hline $\begin{array}{l}\text { Extracorporeal membrane } \\
\text { oxygenation }\end{array}$ & 0 & 0 & 0 & - \\
\hline Re-intubation & $28(5.3)$ & $6(11.8)$ & $22(4.6)$ & 0.03 \\
\hline Tracheostomy & $7(1.3)$ & $1(2.0)$ & $6(1.3)$ & 0.5 \\
\hline Total parenteral nutrition & $6(1.1)$ & $2(3.9)$ & $4(0.8)$ & 0.1 \\
\hline Tube feeds & $36(6.8)$ & $10(19.6)$ & $26(5.4)$ & $<0.001$ \\
\hline Endoscopy & $3(0.6)$ & $2(3.9)$ & $1(0.2)$ & 0.03 \\
\hline Gastrointestinal surgery & 0 & 0 & 0 & - \\
\hline Renal replacement therapy & $9(1.7)$ & $6(11.8)$ & $3(0.6)$ & $<0.001$ \\
\hline \multicolumn{5}{|c|}{$\begin{array}{l}\text { Note: } C F S=\text { Clinical Frailty Scale. } \\
\text { *All comparisons } \chi^{2} \text { tests of independence. } \\
\text { †Acute kidney injury: threefold increase in serum creatinine, serum creatinine exceeding } 353.6 \mu \mathrm{mol} / \mathrm{L} \text { with } \\
\text { minimum rise of } 44.2 \mu \mathrm{mol} / \mathrm{L} \text {, or new initiation of renal replacement therapy. }\end{array}$} \\
\hline
\end{tabular}

be susceptible to recall bias from patients or surrogates when describing self-reported activities, quality of life and functional autonomy before surgery. If and where applicable, recall bias would likely underestimate the prevalence of frailty in our view, as patients may minimize many of their symptoms and be less likely to recognize these as consistent with frailty.

Our study was also relatively small and is predisposed to selection bias owing to inability to compare patients not enrolled, patients who were referred for cardiac surgery but declined, or patients counselled not to undergo surgery. There were few deaths in the CVICU or hospital, so adjusted estimates of the increase in risk of short-term mortality associated with frailty are accompanied by a great deal of uncertainty. No information was gathered related to changes to goals of care throughout the hospital stay, although all patients were designated for full resuscitation care during the perioperative period. Finally, we recognize that the generalizability of our study may be limited in other health jurisdictions. 


\begin{tabular}{|c|c|c|c|}
\hline $\begin{array}{l}\text { Presurgery } \\
\text { CFS score }\end{array}$ & $\begin{array}{c}\text { No. }(\%) \text { of } \\
\text { patients in cohort }\end{array}$ & $\begin{array}{c}\text { Adjusted HR }(95 \% \mathrm{Cl}) \text {, } \\
\text { model } 1^{*}\end{array}$ & $\begin{array}{c}\text { Adjusted HR }(95 \% \mathrm{Cl}) \text {, } \\
\text { model } 2 \dagger\end{array}$ \\
\hline $1-4$ & $478(90.4)$ & 1.00 (Ref.) & 1.00 (Ref.) \\
\hline $5-9$ & $51(9.6)$ & $4.59(1.58-13.28)$ & $4.34(1.54-12.19)$ \\
\hline $1-3$ & $304(57.5)$ & 1.00 (Ref.) & 1.00 (Ref.) \\
\hline 4 & 174 (32.9) & $2.25(0.70-7.21)$ & $1.86(0.56-6.21)$ \\
\hline $5-9$ & $51(9.6)$ & $7.11(1.97-25.71)$ & $6.06(1.71-21.51)$ \\
\hline $1-3$ & $304(57.5)$ & 1.00 (Ref.) & 1.00 (Ref.) \\
\hline 4 & 174 (32.9) & $2.24(0.70-7.18)$ & $1.81(0.54-6.09)$ \\
\hline 5 & $38(7.1)$ & $5.94(1.46-24.13)$ & $4.80(1.20-19.16)$ \\
\hline $6-9$ & $13(2.5)$ & $11.85(2.11-66.69)$ & $12.86(2.30-72.05)$ \\
\hline
\end{tabular}

\section{Conclusion}

Frailty was observed in $10 \%$ of adults aged 50 years and older referred for cardiac surgery. The presence of preoperative frailty was associated with a higher risk of morbidity, mortality and health services use. These findings suggest that routine frailty screening could provide an opportunity to better inform patients, families, caregivers, health professionals and health system administrators about outcomes after cardiac surgery and re-engineer care pathways to better plan for complex care after surgery.

\section{References}

1. Afilalo J, Eisenberg MJ, Morin J-F, et al. Gait speed as an incremental predictor of mortality and major morbidity in elderly patients undergoing cardiac surgery. 7 Am Coll Cardiol 2010;56:1668-76.

2. Lee DH, Buth KJ, Martin B-J, et al. Frail patients are at increased risk for mortality and prolonged institutional care after cardiac surgery. Circulation 2010;121:973-8.

3. Sündermann S, Dademasch A, Rastan A, et al. One-year follow-up of patients undergoing elective cardiac surgery assessed with the Comprehensive Assessment of Frailty test and its simplified form. Interact Cardiovasc Thorac Surg 2011;13:119-23, discussion 23.

4. Clegg A, Young J, Iliffe S, et al. Frailty in elderly people. Lancet 2013;381:752-62.

5. Buth KJ, Gainer RA, Legare J-F, et al. The changing face of cardiac surgery: practice patterns and outcomes 2001-2010. Can F Cardiol 2014;30:224-30.

6. Pierri MD, Capestro F, Zingaro C, et al. The changing face of cardiac surgery patients: an insight into a Mediterranean region. Eur 7 Cardiothorac Surg 2010;38:407-13.

7. Hickey GL, Grant SW, Murphy GJ, et al. Dynamic trends in cardiac surgery: why the logistic EuroSCORE is no longer suitable for contemporary cardiac surgery and implications for future risk models. Eur 7 Cardiothorac Surg 2013;43:1146-52.

8. Mazankowski Alberta Heart Institute. State of the heart: annual report 2017. Edmonton: Alberta Health Services; 2017. Available: www.albertahealthservices. ca/assets/hospitals/maz/maz-annual-report-2016-17.pdf (accessed 2021 Mar. 10).

9. Libin Cardiovascular Institute. 2017-2018 Cardiac Sciences Annual Report. Calgary: Department of Cardiac Sciences, University of Calgary; 2018. Available: https://live-libin.ucalgary.ca/sites/default/files/teams/1/2018-2019\%20 Annual\%20Report_FINAL.pdf (accessed 2021 Mar. 10).

10. Cardiac care quality indicators report. Ottawa: Canadian Institute for Health Information; 2017. Available: https://secure.cihi.ca/free_products/cardiac-care -quality-indicators-report-en-web.pdf (accessed 2021 Mar. 10).

11. van Diepen S, Graham MM, Nagendran J, et al. Predicting cardiovascular intensive care unit readmission after cardiac surgery: derivation and validation of the Alberta Provincial Project for Outcomes Assessment in Coronary Heart Disease (APPROACH) cardiovascular intensive care unit clinical prediction model from a registry cohort of 10,799 surgical cases. Crit Care 2014;18:651.
12. Rockwood K, Song X, MacKnight C, et al. A global clinical measure of fitness and frailty in elderly people. CMA7 2005;173:489-95.

13. Theou O, Brothers TD, Mitnitski A, et al. Operationalization of frailty using eight commonly used scales and comparison of their ability to predict allcause mortality. 7 Am Geriatr Soc 2013;61:1537-51.

14. Hope AA, Hsieh SJ, Petti A, et al. Assessing the usefulness and validity of frailty markers in critically ill adults. Ann Am Thorac Soc 2017;14:952-9.

15. Shears M, Takaoka A, Rochwerg B, et al.; Canadian Critical Care Trials Group. Assessing frailty in the intensive care unit: a reliability and validity study. 7 Crit Care 2018;45:197-203.

16. Bagshaw SM, Stelfox HT, McDermid RC, et al. Association between frailty and short- and long-term outcomes among critically ill patients: a multicentre prospective cohort study. CMA7 2014;186:E95-102.

17. Podsiadlo D, Richardson S. The timed "Up \& Go": a test of basic functional mobility for frail elderly persons. 7 Am Geriatr Soc 1991;39:142-8.

18. Herdman M, Gudex C, Lloyd A, et al. Development and preliminary testing of the new five-level version of EQ-5D (EQ-5D-5L). Qual Life Res 2011;20:1727-36.

19. Orwelius L, Nordlund A, Nordlund P, et al. Pre-existing disease: the most important factor for health related quality of life long-term after critical illness: a prospective, longitudinal, multicentre trial. Crit Care 2010;14:R67.

20. De Smedt D, Clays E, Doyle F, et al.; EUROASPIRE Study Group. Validity and reliability of three commonly used quality of life measures in a large European population of coronary heart disease patients. Int 7 Cardiol 2013;167:2294-9.

21. Nashef SA, Roques F, Sharples LD, et al. EuroSCORE II. Eur 7 Cardiothorac Surg 2012;41:734-44, discussion 744-5.

22. Parsonnet V, Dean D, Bernstein AD. A method of uniform stratification of risk for evaluating the results of surgery in acquired adult heart disease. Circulation 1989;79:13-12.

23. Quan H, Li B, Couris CM, et al. Updating and validating the Charlson comorbidity index and score for risk adjustment in hospital discharge abstracts using data from 6 countries. Am F Epidemiol 2011;173:676-82.

24. Analytics and Performance Reporting Branch; Alberta Health. Overview of administrative health datasets. Government of Alberta; 2017.

25. Ghali WA, Knudtson ML. Overview of the Alberta Provincial Project for Outcome Assessment in Coronary Heart Disease. On behalf of the APPROACH investigators. Can 7 Cardiol 2000;16:1225-30.

26. Yanagawa B, Graham MM, Afilalo J, et al. Frailty as a risk predictor in cardiac surgery: beyond the eyeball test. 7 Thorac Cardiovasc Surg 2018;156: 172-6.e2.

27. Williams JB, McConnell G, Allender JE, et al. One-year results from the first US-based enhanced recovery after cardiac surgery (ERAS Cardiac) program. 7 Thorac Cardiovasc Surg 2019;157:1881-8.

28. Ettema R, Schuurmans MJ, Schutijser B, et al. Feasibility of a nursing intervention to prepare frail older patients for cardiac surgery: a mixed-methods study. Eur 7 Cardiovasc Nurs 2015;14:342-51.

29. Roberts TJ, Matthews JL, Brown PK, et al. Enhanced recovery pathway improves colorectal surgery outcomes in private and safety-net settings. 7 Surg Res 2020;245:354-9.

30. Jansson MM, Harjumaa M, Puhto A-P, et al. Healthcare professionals' perceived problems in fast-track hip and knee arthroplasty: results of a qualitative interview study. 7 Orthop Surg Res 2019;14:294. 
31. Kebapcı A, Kanan N. Effects of nurse-led clinical pathway in coronary artery bypass graft surgery: a quasi-experimental study. 7 Clin Nurs 2018;27:980-8.

32. Negm AM, Kennedy CC, Thabane L, et al. Management of frailty: a systematic review and network meta-analysis of randomized controlled trials. $7 \mathrm{Am}$ Med Dir Assoc 2019;20:1190-8.

33. Waite I, Deshpande R, Baghai M, et al. Home-based preoperative rehabilitation (prehab) to improve physical function and reduce hospital length of stay for frail patients undergoing coronary artery bypass graft and valve surgery. $\mathcal{F}$ Cardiothorac Surg 2017;12:91.

34. Verma G, O'Laughlin JP, Bunker L, et al. Trial of time: review of frailty and cardiovascular disease. Cardiol Rev 2017;25:236-40.

35. Sawatzky JA, Kehler DS, Ready AE, et al. Prehabilitation program for elective coronary artery bypass graft surgery patients: a pilot randomized controlled study. Clin Rehabil 2014;28:648-57.

36. Laur CV, McNicholl T, Valaitis R, et al. Malnutrition or frailty? Overlap and evidence gaps in the diagnosis and treatment of frailty and malnutrition. Appl Physiol Nutr Metab 2017;42:449-58.

37. Allard JP, Keller H, Jeejeebhoy KN, et al. Malnutrition at hospital admission: contributors and effect on length of stay - a prospective cohort study from the Canadian Malnutrition Task Force. FPEN 7 Parenter Enteral Nutr 2016; 40:487-97.

38. Partridge JS, Harari D, Dhesi JK. Frailty in the older surgical patient: a review. Age Ageing 2012;41:142-7.

39. Gainer R, Buth K, Legare J, et al. The changing face of cardiac surgery: frailty, age, and adverse outcomes create a mandate for shared decision making [abstract]. Can 7 Cardiol 2013;29(Suppl):S209.

40. Moorhouse P, Rockwood K. Frailty and its quantitative clinical evaluation. $\mathcal{f}$ $R$ Coll Physicians Edinb 2012;42:333-40.

41. Gainer RA, Curran J, Buth KJ, et al. Toward optimal decision making among vulnerable patients referred for cardiac surgery: a qualitative analysis of patient and provider perspectives. Med Decis Making 2017;37:600-10.

42. Stow D, Spiers G, Matthews FE, et al. What is the evidence that people with frailty have needs for palliative care at the end of life? A systematic review and narrative synthesis. Palliat Med 2019;33:399-414.

43. Kimber DE, Kehler DS, Lytwyn J, et al. Pre-operative frailty status is associated with cardiac rehabilitation completion: a retrospective cohort study. $\mathcal{F}$ Clin Med 2018;7:560.

44. Montgomery CL, Rolfson DB, Bagshaw SM. Frailty and the association between long-term recovery after intensive care unit admission. Crit Care Clin 2018;34:527-47.

45. Miguelena-Hycka J, Lopez-Menendez J, Prada P-C, et al. Influence of preoperative frailty on health-related quality of life after cardiac surgery. Ann Thorac Surg 2019;108:23-9.

46. Kotajarvi BR, Schafer MJ, Atkinson EJ, et al. The impact of frailty on patient-centered outcomes following aortic valve replacement. 7 Gerontol A Biol Sci Med Sci 2017;72:917-21.

47. $\mathrm{Li} Z$, Ding $X$. The incremental predictive value of frailty measures in elderly patients undergoing cardiac surgery: a systematic review. Clin Cardiol 2018; 41:1103-10.

48. Lytwyn J, Stammers AN, Kehler DS, et al. The impact of frailty on functional survival in patients 1 year after cardiac surgery. 7 Thorac Cardiovasc Surg 2017; 154:1990-9.

49. Searle SD, Mitnitski A, Gahbauer EA, et al. A standard procedure for creating a frailty index. BMC Geriatr 2008;8:24.

50. Mitnitski AB, Mogilner AJ, Rockwood K. Accumulation of deficits as a proxy measure of aging. ScientificWorldfournal 2001;1:323-36.
Affiliations: Department of Critical Care Medicine (Montgomery, Zibdawi, Bagshaw), Faculty of Medicine \& Dentistry, University of Alberta, Edmonton, Alta.; Department of Critical Care Medicine (Stelfox), Cumming School of Medicine, and Department of Community Health Sciences (Stelfox), University of Calgary, Calgary, Alta.; Faculty of Nursing and School of Public Health (Norris, Bagshaw), University of Alberta; Strategic Clinical Networks (Norris, Bagshaw), Alberta Health Services; Division of Geriatric Medicine (Rolfson), Department of Medicine, and Division of Cardiac Surgery, (Meyer) Department of Surgery, Faculty of Medicine \& Dentistry, University of Alberta, Edmonton, Alta.

Contributors: Sean Bagshaw, Henry Stelfox, Darryl Rolfson, Mohamad Zibdawi, Colleen Norris and Steven Meyer planned and designed this study. Sean Bagshaw and Colleen Norris oversaw data collection. Carmel Montgomery performed data analysis and drafted the manuscript. All authors revised the article, gave final approval of the version to be published and agreed to be accountable for all aspects of the work.

Funding: This work was funded by a grant from the MSI Foundation (Alberta Grant \# 2012-863). The funding agency had no role in the design or conduct of the study, in the collection, management, analysis or interpretation of the data, or in the preparation, review or approval of the manuscript.

Content licence: This is an Open Access article distributed in accordance with the terms of the Creative Commons Attribution (CC BY-NC-ND 4.0) licence, which permits use, distribution and reproduction in any medium, provided that the original publication is properly cited, the use is noncommercial (i.e., research or educational use), and no modifications or adaptations are made. See: https://creativecommons.org/licenses/ by-nc-nd/4.0/

Data sharing: Data used in this study may be shared for the purposes of medical research and under the auspices of the consent under which the data were originally collected. Deidentified individual patient data will be available for sharing 1 year after publication of the primary analysis. Data will be made available to qualified researchers who provide a detailed and methodologically sound proposal with specific aims that are clearly outlined. To gain access, qualified researchers will need to sign a data sharing and access agreement and will need to confirm that data will be used only for the agreed upon purpose for which data access was granted. Contact the corresponding author for further details.

Acknowledgements: The authors acknowledge the following individuals from the University of Alberta and University of Calgary critical care research departments whose work was essential to the completion of this study: Nadia Baig, Colleen McKee, Kristen Reid and Lily Yushko.

Supplemental information: For reviewer comments and the original submission of this manuscript, please see www.cmajopen.ca/content/9/3/ E777/suppl/DC1. 